\title{
Evaluating the Skills for Writing Referencing Styles in the Assignments of Aesthetic Studies Undergraduates: Case Study at Eastern University, Sri Lanka
}

\author{
By Mr. B. Prashanthan, MAC.Fathima Aroosiya \& Ibnu Suhood Narsheeth
}

Eastern University

Abstract- Writing appropriate Referencing style is identified as a skill among the academic researchers in the higher education society. It plays a significant role in assignments process. If research or assignment used appropriate referencing style that particular document becomes high-quality document. In this context this paper analyses the skill for writing-different referencing styles in aesthetic Studies Undergraduate assignments. The study used the survey research design through the stratified random sampling method, 75 out of 164 undergraduates were selected as sample. Referencing skill was evaluated through three categories (referencing style the format of Books, periodicals and Non-print source). This study was carried out by pretest and posttest. Before the one month of post-test, two days seminar was conducted about referencing style. According to the pre-test result, the overall level for the undergraduates' performance of writing referencing style in their assignments is $28.33 \%$. However, due to the two days' workshop knowledge about the usage of referencing style was increasing all categories. The referencing style for books were increased from $43.33 \%$ to $51.66 \%$, for periodicals were increased from $26.6 \%$ to $33.33 \%$, for non-print sources were increased from $15 \%$ to $18.33 \%$, and the overall performance was $34.44 \%$, but level is not in satisfactory level.

Keywords: referencing style, aesthetic, assignment.

GJHSS-G Classification: FOR Code: 199999

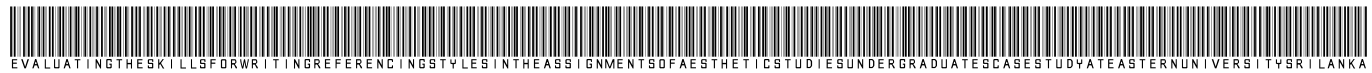

Strictly as per the compliance and regulations of:

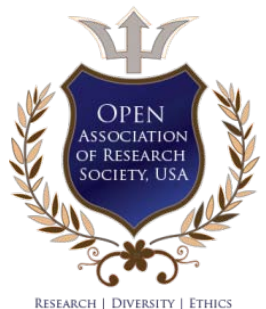

(C) 2019. Mr. B. Prashanthan, MAC.Fathima Aroosiya \& Ibnu Suhood Narsheeth. This is a research/review paper, distributed under the terms of the Creative Commons Attribution-Noncommercial 3.0 Unported License http://creativecommons.org/licenses/by-nc/3.0/), permitting all non-commercial use, distribution, and reproduction in any medium, provided the original work is properly cited. 


\title{
Evaluating the Skills for Writing Referencing Styles in the Assignments of Aesthetic Studies Undergraduates: Case Study at Eastern University, Sri Lanka
}

\author{
Mr. B. Prashanthan ${ }^{\alpha}$, MAC.Fathima Aroosiya ${ }^{\sigma} \&$ Ibnu Suhood Narsheeth $^{\rho}$
}

Abstract-Writing appropriate Referencing style is identified as a skill among the academic researchers in the higher education society. It plays a significant role in assignments process. If research or assignment used appropriate referencing style that particular document becomes highquality document. In this context this paper analyses the skill for writing-different referencing styles in aesthetic Studies Undergraduate assignments. The study used the survey research design through the stratified random sampling method, 75 out of 164 undergraduates were selected as sample. Referencing skill was evaluated through three categories (referencing style the format of Books, periodicals and Non-print source). This study was carried out by pretest and posttest. Before the one month of post-test, two days seminar was conducted about referencing style. According to the pre-test result, the overall level for the undergraduates' performance of writing referencing style in their assignments is 28.33\%. However, due to the two days' workshop knowledge about the usage of referencing style was increasing all categories. The referencing style for books were increased from $43.33 \%$ to $51.66 \%$, for periodicals were increased from $26.6 \%$ to $33.33 \%$, for non-print sources were increased from $15 \%$ to $18.33 \%$, and the overall performance was $34.44 \%$, but level is not in satisfactory level. The study reveals that aesthetic studies undergraduates do not have enough knowledge in referencing style. As a whole, if it essential to improve the referencing style among the undergraduates for their assignments writing and it helps for their future research works. Therefore, this study suggested organizes several workshops to upgrade the skill in the referencing style.

Keywords: referencing style, aesthetic, assignment.

\section{InTRODUCTION}

T he current development technologies provide a huge amount of information within a minute; information was obtained in different formats. In this scenario, access, organize and using appropriate

Corresponding Author $\alpha$ : Senior Asst. Librarian Swamy Vipulananda Institute of Aesthetic Studies. Eastern University, Sri Lanka

e-mail:Prashsh3y@gmail.com

Author $\sigma$ : Senior Assistant Registrar, Swamy Vipulananda Institute of Aesthetic Studies. Eastern University, Sri Lanka.

e-mail: fathimaaroosiya@gmail.com

Author p: Senior Assistant Registrar UvaWellassa University of Sri Lanka. e-mail:narsheeth@uwu.ac.lk printed and electronic information resources becomes an essential requirement in the contemporary era. In the context of University education, writing of assignments are an integral part of the learners, to expand knowledge in specific disciplines, engage in learning and research. In the meantime, writing and organizing the references, in particular referencing style plays a significant role in the academic assignments writing process. If it's used appropriate reference style, that particular document or research becomes high-quality reference and helps to avoid plagiarism. But it is a challenge for undergraduate in the present information era, where the information is abundant. According to Mashroofa (2009) "Information, overload is a frequent complaint within these environments. Because of the complexity of these environments, undergraduate face with diverse and abundant information choices in their academic studies" taking into consideration of these factors undergraduates should be guided to acquire proper skills for using reference system. In this background, this study aims to evaluate the knowledge and for writing different referencing style in the final year esthetic Studies Undergraduates assignments at Eastern University, Sri Lanka. Although there are different reference management software like End Note, Mendeley etc; it is difficult to use this software in aesthetic studies assignments and the medium for conducting all academic programme in tamil at Swami Vipulananda Institute of Aesthetic Studies. The available software does not support the local language properly. Moreover, available literature on various referencing styles is also in English, by which the students in aesthetic studies struggle to write the references in their assignments and reports. Therefore students have to be trained for different referencing styles manually. The undergraduate follows esthetic studies at the Swami Vipulananda Institute of Aesthetic Studies, which was merged as a higher education institute with Eastern University, Sri Lanka officially in $14^{\text {th }}$ March 2005.The Institute has three departments such as Department of Music, Department of Dance, Drama and Theater Arts and Department of Visual Technological Arts. 


\section{Statement of the Problem}

Referencing style has been a subject of concern to an undergraduate in most of the Aesthetic studies. Also, the lack of appropriate knowledge in writing referencing style in assignments has become worrisome for all undergraduate. It was observed while the undergraduate students submit assignments throughout their study programme. Therefore, the study intended to carry out on evaluating their Skills for writing Referencing Styles in the Assignments of Aesthetic Studies Undergraduates.

\section{il. Objectives of the Study}

The objective of the study is

- To investigate the use of reference skill of aesthetic studies undergraduate in their assignments

- To examine the use of referencing styles for different formats of information sources (Books, Periodicals, and Nonprint sources) in Undergraduates assignments.

- To suggest the remedies for undergraduates to write the reference more effectively.

\section{ili. Methodology}

Descriptive survey method has been used for this study and observation chart has been used as the data collecting instrument. The target population included in the study was all final year students of the academic year of 2009/2010, enrolled in Swami Vipulananda Institute of Aesthetic Studies, Eastern University Sri Lanka. The sample size calculated as per Barletta. (2001). accordingly, the sample size for the present study is 75 as the population size is 164 . However, only 60 students have responded for this study. Therefore the response rate of present study is 80 $\%$. The sample was selected through stratified random sampling. The undergraduates' population was satisfied into two categories, according to their field of study and gender.

In this study, a pre-observation (pre-test) carried out with undergraduate's assignment in 2014 October. The researcher conducted a workshop on different referencing styles consisting of three sub topic. The programs conducted for two days and at the end of the program (after one month of a program) a post observation (post-test) was carried out with undergraduates' new assignments. The collected data were analyzed using SPSS statistical software for descriptive statistics.

\section{Results and Discussion}

Since the aesthetic studies undergraduate mostly use books, periodicals and non-print sources for their assignments, the data analysis was limited only to three categories such as referencing style for the format of Books, Periodicals and Non print sources. According to the pre-test, it was noted that the highest percentage of aesthetics studies undergraduates (56.67\%) were not familiar with for the referencing style for books. Likewise, the Undergraduates were also not familiar in referencing styles of non- print sources and Periodicals. In the pretest, $15 \%$ of the students wrote appropriate reference for non-print sources and only $26.66 \%$ of the students wrote an appropriate reference periodical. Overall performance in writing different reference style in undergraduates' assignments was not in the satisfactory level that is Majority of students (71.67\%) was not familiar with the use of reference in an appropriate way. The results are given Table 01.

Table 1: From Pre-observation

\begin{tabular}{|c|c|c|}
\hline \multirow{2}{*}{ Category } & \multicolumn{2}{|c|}{$\begin{array}{c}\text { Writing appropriate reference } \\
\text { styles }\end{array}$} \\
\cline { 2 - 3 } & Undergraduates & Percentage \\
\hline Books & 26 & $43.33 \%$ \\
\hline Periodicals & 16 & $26.66 \%$ \\
\hline Non-print sources & 09 & $15 \%$ \\
\hline
\end{tabular}

The performance levels of writing referencing styles in undergraduate assignment after the post observation are given table 02.

\section{Table 2: From Post-observation}

\begin{tabular}{|c|c|c|}
\hline \multirow{2}{*}{ Category } & \multicolumn{2}{|c|}{$\begin{array}{c}\text { Writing appropriate reference } \\
\text { style }\end{array}$} \\
\cline { 2 - 3 } & Undergraduates & Percentage \\
\hline Books & 31 & $51.66 \%$ \\
\hline Periodicals & 20 & $33.33 \%$ \\
\hline Non print sources & 11 & $18.33 \%$ \\
\hline
\end{tabular}

The result of post-test indicates that the skills for writing different referencing styles in the assignments of aesthetic studies undergraduates after conducting two days' workshop were slightly increased in all categories. The in-depth analysis showed that the overall performance of appropriate referencing style level was increased by $6.11 \%$, which ranges from $2.16 \%$ to $8.33 \%$. The writing skill referencing style for periodical was increased by $6.67 \%$, for non-print sources it was increased by $2.16 \%$, and for books it was increased by $8.35 \%$. However, the overall increase did not exceed the $50 \%$, but it was only $34.44 \%$. In the comparison of preobservation and post-observation for writing referencing style in their assignment is given in table 03.

Table 3: From Pre-observation and Post-observation

\begin{tabular}{|c|c|c|}
\hline Category & $\begin{array}{c}\text { Pre- } \\
\text { observation }\end{array}$ & Post-observation \\
\hline Books & $43.33 \%$ & $51.66 \%$ \\
\hline Periodicals & $26.66 \%$ & $33.33 \%$ \\
\hline Non print sources & $15 \%$ & $18.33 \%$ \\
\hline Overall & $28.33 \%$ & $34.44 \%$ \\
\hline
\end{tabular}




\section{Conclusions and Recommendations}

According to this study, the overall average level in the usage of referencing style in Undergraduates assignment was at needs improvement level. Further, the study reveals that due to the two days' workshop knowledge about the usage of referencing style at the assignment of aesthetics studies undergraduates was slightly increased in all categories. But those levels are not even in a satisfactory level. Therefore the skills for writing referencing styles should be improved in an appropriate way among the aesthetic studies undergraduates from in their first-year studies. Hence, the following recommendation can be made to develop the undergraduate referencing style.

The Institute should plan and arrange short term awareness program and workshop at regular intervals to develop the referencing skill among students. They need training especially on non-print sources referencing and periodical reference style. Therefore Institute should consider the time duration and the length to the program to be relevant to Undergraduates.

\section{References Références Referencias}

1. Association College of Research Libraries.(2000). Information literacy competency standards for higher education. Retrieved from http: // www.acrl .org/ ala/ mgrps /divs /acrl/standards. Pdf.

2. Bartlett, Kotrlik, and Higgins. (2001). Organization research: Determining appropriate sample size in survey research. Information technology learning and performance. Journal, 19(1), 43-50.

3. Burton, Vicki Tolar, and Chadwick, Scott. Investigating the practices of student researchers: patterns of use and criteria for use of internet and Library sources (as cited in Lizette King.2007) provided Information literacy of incoming Undergraduate Arts Students at the University of Western Cape. PhD Dissertation.

4. Beger, Arthur Asa, (2009). The Academic Writer's toolkit: A user's manual. New Delhi, PHI Learning Private LTD.

5. Doyle Christine. S. (1993). The Delphi Method as a Qualitative Assessment tool for development outcome measures for information literacy. School Library media annual 11, 132 - 144

6. Mashroofa, M.M. (2009). New vistas of information literacy education a case from South Eastern University. Journal of the University Librarians Association of Sri Lanka, 13, 23-36.

7. Ranaweera, Prasanna. (2010). Information Literacy program conducted by the Universities in Sri Lanka. Journal of the University Librarians Association of Sri Lanka, 11, $61-74$.

8. Somaratna, S.(2011). Enhancing the quality process of undergraduates of the facility of science, University of Colombo by incorporeity and information skills development program in to the curriculums. Conference paper presented on SLAIHEE conference. May 2011

9. University of Bath. (n d).Plagiarism and Referencing. Retrieved from www.bath.ac.uk/library/.../referencing Plagiarism. 